\title{
RESIN YIELD AND TIMBER QUALITY OF Pinus caribaea TREES TAPPED USING RILL METHOD
}

\author{
S P Bamunusinghe ${ }^{1}$, H S Amarasekera ${ }^{1}$ and M P S Fernando ${ }^{2}$ \\ ${ }^{1}$ Department of Forestry and Environmental Science \\ University of Sri Jayewardenepura, Nugegoda \\ ${ }^{2}$ Forest Department, Battaramulla.
}

Experiments to study the oleo-resin yield in different diameter trees, tapping depths and tapping heights were under taken in the wet zone in the Kalutara District. Oleo-resin yield was measured in Pinus caribaea trees belonging to two diameter classes $(10 \mathrm{~cm}-20 \mathrm{~cm}$ $\mathrm{DBH},>20 \mathrm{~cm}$ DBH classes), two tapping heights above ground $(0.5 \mathrm{~m}$ and $1.3 \mathrm{~m})$ and three tapping depths ( $1 \mathrm{~mm}, 2 \mathrm{~mm}$ and $5 \mathrm{~mm}$ ).

Results showed that oleo-resin yield was higher in larger diameter classes compared with lower diameter classes. Resin yield was also higher at $1.3 \mathrm{~m}$ tapping height compared with $0.5 \mathrm{~m}$ height. Resin yield also increased as the tapping depth increased from $1 \mathrm{~mm}$ to 5 $\mathrm{mm}$. Based on these data it is recommended that the lowest tappable limit may be above $20 \mathrm{~cm} \mathrm{DBH}$ and it can expected to increase the yield of oleo-resin as well as health and vigour of the tree. It is suggested the height of tapping should be increased to yield more oleo-resin. However the cost of tapping would increase when higher heights are to be used. A $5 \mathrm{~mm}$ depth starting from the live bark can be recommended as suitable depth in resin tapping. This depth can increase the yield of oleo-resin while maintaining the health and vigour of the tree.

Experiments to study the growth rate and timber quality of tapped and untapped $P$. caribaea trees were also done by measuring density and width of the rings. Log samples for this experiment were obtained from plantation at Guruthalawa in the Badulla district. At the time of sampling these trees had been tapped for 5 years.

There were three tapped and three untapped trees which belonged to 3 diameter classes $(20 \mathrm{~cm}, 28 \mathrm{~cm}, 36.5 \mathrm{~cm})$. Each couple of tapped and untapped tree had the same diameter. For each tree, discs were extracted at $0.5 \mathrm{~m}$ height and $1.3 \mathrm{~m}$ height. The width of growth rings which is a measure of growth rate, were measured on untapped tree, tapped radius and untapped radius in tapped tree. The data showed that wood production has not been affected considerably by resin tapping.

The density which is an indicator for wood quality showed an increasing trend from pith outwards. Density in the tapped trees was higher due to infiltration of oleo-resin into the wood after resin tapping. Except this variation, no other considerable difference was observed in density between tapped and untapped trees.

Proceedings of the Third Annual Forestry Symposium 1997, of the Department of Forestry and Environmental Science, University of Sri Jayewardenepura, Sri Lanka 